\title{
Comparison of speed and accuracy between manual and computer-aided measurements of dental arch and jaw arch lengths in study model casts
}

\author{
Dinah Wibisono, Bergman Thahar, Tono S. Hambali, Jono Salim \\ Department of Orthodontic, Faculty of Dentistry, Universitas Padjadjaran
}

\begin{abstract}
This research is aimed at observing whether there are differences in the measurement results between dental arch length and arch length measured manually and by using computer software, i.e. Corel Draw 12, in study model cast as well as the measurement speed in both techniques. The method used in this research is the descriptive comparative method. The measurement is performed to 52 study model cast samples with the Spee Curve depth of $<1.5 \mathrm{~mm}$, between 1.5 and $3 \mathrm{~mm},>3 \mathrm{~mm}$. The measurements are performed using 2 techniques: manual technique using caliper and by using Corel Draw 12, a computer program with computer scanner. The t-test statistic is used to reveal whether there are differences in the measurement results between the two techniques and which method needs shorter time. Statistically, there are significant differences either in the speed of the measurement or the results of the measurement using both technique where $t$-calculated $>t$ table. The deeper the Spee curve, the more different the results from the manual technique and computed technique. The differences are in the range of 0.32 to $0.52 \mathrm{~mm}$ for dental arch length and 0.33 to $0.43 \mathrm{~mm}$ for arch length. These differences are still acceptable clinically. By referring to the results of this research, it is expected that computer usage can be increased and become an alternative against manual technique of measurement.
\end{abstract}

Key words: Dental arch length measurement, speed of the measurement, manual technique, Corel Draw $12^{R}$

\section{INTRODUCTION}

A study model cast is a standard component of information source for diagnosing and planning the treatment of a special case. Other components include facial and intra-oral photographs, x-ray photographs, and medical record cards. ${ }^{1,2}$ From a study model cast, it is possible to obtain information about dental shape, dimension, condition, and position, and length of jaw arch. A study model cast also gives us a three-dimensional image of the intra-oral condition. ${ }^{1,3}$ Dividers, Boley Gauge,
Vernier Gauge, and electronic digital calipers are among the instruments commonly used to measure mesio-dental width. , $, 5,6,7$ For manual measurement of jaw arch length, dividers or brass wire are often used. ${ }^{8}$

A patent on a computer model system that can generate digital images from a study model cast has been granted to ORTHOCAD (Cadent Fairview, NJ). ORTHOCAD produces a software program that can be operated by orthodontists to perform study model cast routine measurements of dental dimension, overjet, overbite, and to perform 
Bolton analysis. The software can also generate multi-angle images of upper jaw occlusion. ${ }^{2,9}$

Measurement of dental and jaw arch length in a study model cast has been performed manually with a pair of sharp-pointed dividers. With the current development in computer technology, there is now available in market a software program called Corel Draw 12, which can be used to create graphic designs. There is also a scanner that can convert an image into a digital format with the help of a computer set. The present writer conceives this technological development as interesting. If the combined use of a computer set, software program, and scanner can be applied in the field of orthodontics to produce accurate and reliable results, especially from a study model cast, it is then possible to store the information from a study model cast in a digital or electronic format. The technology can be very useful in orthodontic information management. With this technology, an orthodontist can quickly retrieve the required dental information and communicate it to the patient. ${ }^{2,10}$

Since time is now a major concern for most individuals, a computer-aided procedure can be conceived as a way to get things done more quickly and easily. Both manual and computeraided study model measurements have their own procedures. The more a practitioner is accustomed to a new system, the faster and more accurate the measurement is..$^{1,11}$ The research aims to compare the speed and accuracy between manual and computer-aided measurements of dental arch and jaw arch lengths of study model casts.

\section{METHOD}

The research employed the descriptivecomparative method, by which data are analyzed with Student's t-Test. A total of 53 study model casts are sampled. The samples consisted of 19 study model casts with Spee's Curve depths of $<1.5 \mathrm{~mm}, 18$ study model casts with Spee's curve depths of 1.5 to $3 \mathrm{~mm}$, and 15 study model casts with Spee's curve depths of over $3 \mathrm{~mm}$.

The sample criteria ${ }^{1,2}$ were as follows: permanent teeth have erupted from right to left first molar; there are no missing teeth between right first molar and left first molar; occlusion of upper jaw teeth follows lower jaw Spee's curve (no openbite anterior or posterior); depth difference between left and right Spee's curves does not exceed $0.5 \mathrm{~mm}$; there was no abnormality in dental anatomy, no broken teeth in the study models; no airbulbs in study model casts; no attrition, caries, or fillings that can alter the mesio-distal measurement of dental crowns.

Manual measurements of the 52 study model casts were performed in the following manner: Dental arch and jaw arch lengths are measured with a pair of dividers; measurement results are recorded; speed is measured with a stopwatch. Computer-aided measurement follows the following procedure: the study model casts are scanned, the results of which are fed into Corel Draw 12 computer software program. Dental arch length is measured by placing points with a computer mouse on wider mesio-distals as they appear on the monitor screen.

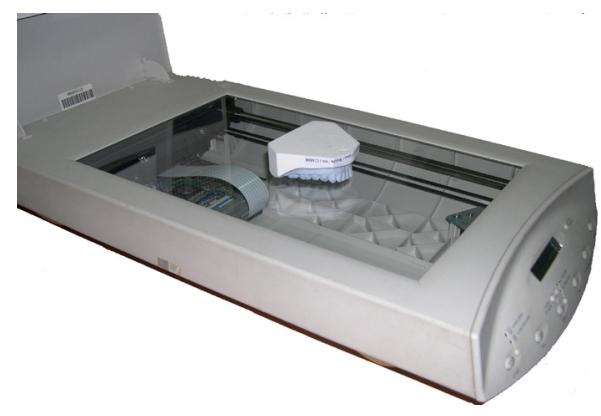

Figure 1. Lower jaw study model cast is placed on scanner
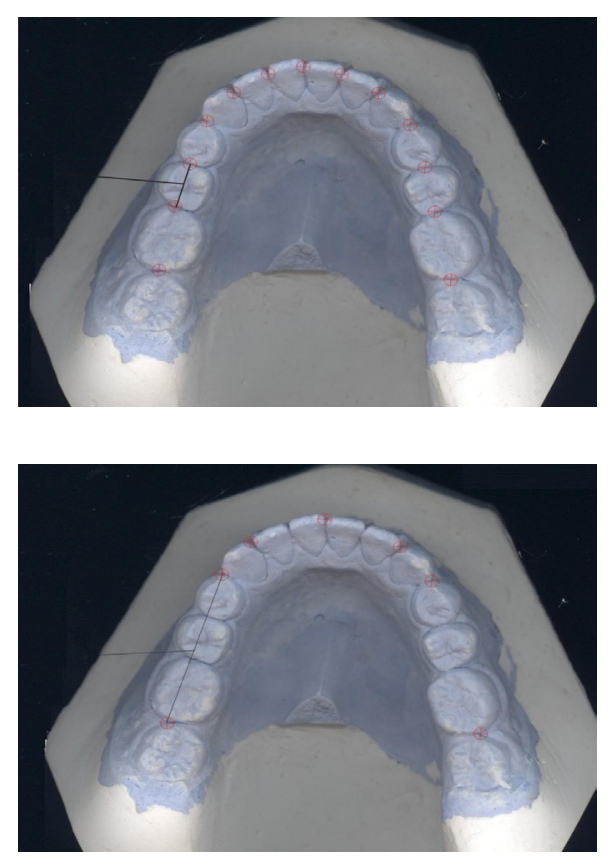

Figure 2. Measurement of interdental width 
Table 1. Analysis of average identicality test between the results of manual and computer-aided measurements of dental arch length

\begin{tabular}{|c|c|c|c|c|c|c|c|}
\hline \multirow{2}{*}{ Spee's curve } & \multirow{2}{*}{ Statistics } & \multicolumn{3}{|c|}{ UJ } & \multicolumn{3}{|c|}{ LJ } \\
\hline & & $M$ & $C$ & $\mathrm{t}$ & $M$ & $C$ & $\mathrm{t}$ \\
\hline$<1.5 \mathrm{~mm}$ & $\begin{array}{c}x \\
\text { Std } \\
n \\
\text { t cal } \\
\text { t tab }\end{array}$ & $\begin{array}{c}94.51 \\
3.666 \\
19\end{array}$ & $\begin{array}{c}94.86 \\
3.692 \\
19\end{array}$ & $\begin{array}{c}15.33 \\
2.11\end{array}$ & $\begin{array}{c}86.65 \\
3.459 \\
19\end{array}$ & $\begin{array}{c}87.02 \\
3.438 \\
19\end{array}$ & $\begin{array}{c}16.01 \\
2.11\end{array}$ \\
\hline $1.5-3 \mathrm{~mm}$ & $\begin{array}{c}x \\
\text { Std } \\
n \\
t \mathrm{cal} \\
\mathrm{t} \text { tab }\end{array}$ & $\begin{array}{c}95.68 \\
3.807 \\
18\end{array}$ & $\begin{array}{c}96.09 \\
3.836 \\
18\end{array}$ & $\begin{array}{c}17.23 \\
2.12\end{array}$ & $\begin{array}{c}86.97 \\
3.996 \\
18\end{array}$ & $\begin{array}{c}87.37 \\
3.943 \\
18\end{array}$ & $\begin{array}{c}12.75 \\
2.12\end{array}$ \\
\hline$>3 \mathrm{~mm}$ & $\begin{array}{c}x \\
\text { Std } \\
n \\
t \text { cal } \\
t \text { tab }\end{array}$ & $\begin{array}{c}96.16 \\
2.853 \\
15\end{array}$ & $\begin{array}{c}96.68 \\
2.826 \\
15\end{array}$ & $\begin{array}{c}17.57 \\
2.14\end{array}$ & $\begin{array}{c}87.97 \\
2.741 \\
15\end{array}$ & $\begin{array}{c}88.47 \\
2.786 \\
15\end{array}$ & $\begin{array}{c}16.20 \\
2.14\end{array}$ \\
\hline
\end{tabular}

Table 2. Analysis of average identicality test between the results of manual and computer-aided measurements of jaw arch length

\begin{tabular}{|c|c|c|c|c|c|c|c|}
\hline \multirow{2}{*}{ Spee's curve } & \multirow{2}{*}{ Statistics } & \multicolumn{3}{|c|}{ UJ } & \multicolumn{3}{|c|}{ LJ } \\
\hline & & $M$ & $\mathrm{C}$ & $\mathrm{t}$ & $M$ & C & $t$ \\
\hline$<1.5 \mathrm{~mm}$ & $\begin{array}{c}x \\
S D \\
n \\
\text { t cal } \\
\text { t tab }\end{array}$ & $\begin{array}{c}91.55 \\
4.971 \\
19\end{array}$ & $\begin{array}{c}91.89 \\
4.967 \\
19\end{array}$ & $\begin{array}{c}13.93 \\
2.11\end{array}$ & $\begin{array}{c}84.11 \\
3.921 \\
19\end{array}$ & $\begin{array}{c}84.43 \\
3.922 \\
19\end{array}$ & $\begin{array}{c}11.47 \\
2.11\end{array}$ \\
\hline $1.5-3 \mathrm{~mm}$ & $\begin{array}{c}\mathrm{x} \\
\mathrm{SD} \\
\mathrm{n} \\
\mathrm{t} \mathrm{cal} \\
\mathrm{t} \text { tab }\end{array}$ & $\begin{array}{c}92.19 \\
4.351 \\
18\end{array}$ & $\begin{array}{c}92.57 \\
4.393 \\
18\end{array}$ & $\begin{array}{c}15.12 \\
2.12\end{array}$ & $\begin{array}{c}84.91 \\
4.692 \\
18\end{array}$ & $\begin{array}{c}85.30 \\
4.697 \\
18\end{array}$ & $\begin{array}{l}12.47 \\
2.12\end{array}$ \\
\hline$>3 \mathrm{~mm}$ & $\begin{array}{c}x \\
S D \\
n \\
t \text { cal } \\
t \text { tab }\end{array}$ & $\begin{array}{c}92.71 \\
4.344 \\
15\end{array}$ & $\begin{array}{c}93.13 \\
4.370 \\
15\end{array}$ & $\begin{array}{c}18.70 \\
2.14\end{array}$ & $\begin{array}{c}84.23 \\
3.971 \\
15\end{array}$ & $\begin{array}{c}84.67 \\
3.990 \\
15\end{array}$ & $\begin{array}{c}16.04 \\
2.14\end{array}$ \\
\hline
\end{tabular}

Table 3. Analysis of identicality test between manual and computer-aided dental arch and jaw arch length measurement speed

\begin{tabular}{|c|c|c|c|c|c|c|}
\hline \multirow{2}{*}{ Spee's curve } & \multirow{2}{*}{ Statistics } & \multicolumn{3}{|c|}{ Time (second) } & \multirow[b]{3}{*}{ Note: } & \multirow{11}{*}{$\begin{array}{l}\text { Upper Jaw } \\
\text { Average } \\
\text { Lower Jaw } \\
\text { Standard Deviation } \\
\text { Manual (milimeter) } \\
\text { Number of Study Model Casts } \\
\text { Computer-aided (milimeter) } \\
\text { Calculated t } \\
\text { Significant } \\
\text { t-table }\end{array}$} \\
\hline & & $M$ & C & $\mathrm{t}$ & & \\
\hline \multirow[t]{4}{*}{$<1.5 \mathrm{~mm}$} & $\underset{c t g}{x}$ & 810.2 & 961.3 & - & & \\
\hline & Std & 12.77 & 9.22 & - & UJ & \\
\hline & $\begin{array}{c}n \\
t \mathrm{cal}\end{array}$ & $\begin{array}{l}19 \\
-\end{array}$ & - & $\left.-64.38^{*}\right)$ & $x$ & \\
\hline & $\mathrm{t}$ tab & - & - & 2. 11 & & \\
\hline \multirow[t]{5}{*}{$1.5-3 \mathrm{~mm}$} & $x$ & 809.6 & 949.6 & - & $M$ & \\
\hline & Std & 13. 49 & 14.17 & - & $\mathrm{n}$ & \\
\hline & $\mathrm{n}$ & 18 & 18 & - & & \\
\hline & $\mathrm{t}$ cal & - & & $\left.-38.26^{*}\right)$ & t hit & \\
\hline & $\mathrm{t} \mathrm{tab}$ & - & & 2. 12 & $\begin{array}{l}\left.{ }^{*}\right) \\
\text { t tab }\end{array}$ & \\
\hline \multirow{5}{*}{$>3 \mathrm{~mm}$} & $x$ & 809.3 & 953.8 & - & & \\
\hline & Std & 15. 37 & 10. 07 & - & & \\
\hline & $\mathrm{n}$ & 15 & 15 & - & & \\
\hline & t cal & - & - & $\left.-36.69^{*}\right)$ & & \\
\hline & $\mathrm{t}$ tab & - & - & 2. 14 & & \\
\hline
\end{tabular}


The process starts from the first right permanent molar distal end to the first left permanent molar distal end. Length reading speed is measured with a stopwatch. Measurement results are then recorded. Jaw arch length is measured by placing points on the alveolar ridges of the 6 segments, from the distal end of the first permanent right molar to the distal end of the first permanent left molar.

Measured lengths are then recorded. A stopwatch is used to measure the speed of jaw arch length measurement. The research is undertaken at the Postgraduate Clinic of the Faculty of Dentistry from September 2005 to Desember 2006. The population of the research was the 516 study model casts of patients of the Orthodontic Specialist Clinic, The Faculty of Dentistry, Universitas Padjadjaran, between 2002 and 2005, before and after orthodontic braces placement.

\section{RESULTS}

Dental arch length measurement variables are shown in table 1 . Jaw arch length measurement variables are shown in table 2 . Comparison of dental arch and jaw arch length measurement speed between the manual and computer-aided techniques is presented in table 3.

\section{Analysis}

Statistically, the overall results of manual and computer-aided measurement techniques show significant differences. This means that the manual and computer-aided measurements of dental arch and jaw arch lengths of model study casts with different Spee's curve depths $(<1.5$ $\mathrm{mm}, 1.5-3 \mathrm{~mm}$, and $>3 \mathrm{~mm}$ ) will yield different values.

The results of computer-aided measurements of dental arch and jaw arch lengths were greater in values than those of the manual technique. The deeper the cast Spee's curve, the greater the difference. This finding is supported by previous studies, that the results of computer-aided measurements are greater in values than those of the manual technique. Errors in the form of value augmentation and diminution may occur due to the position of the dental cast away from the scanner glass surface. Another factor that can cause differences is the placement of identification points on the monitor screen. ${ }^{2,6}$ Difficulties in placing points on the study model cast image on the monitor screen affect the accuracy of the measurement.

From a statistical point of view, the differences in results between the manual and computer-aided techniques were significant. However, a less-than- $0.5 \mathrm{~mm}$. Margin will make virtually no difference in dental diagnoses and treatment plans. In the manual measurement of a study model cast, in which a ruler and a pair of dividers are used, it is a common practice to round values up or down to a margin of $0.5 \mathrm{~mm}$. In space analysis, jaw arch length in this case, it is sufficient to round values up or down to a 0.5 mm margin. ${ }^{12}$

Previous researches agree that such a margin will not result in significant clinical impacts. It takes more time for the computer-aided technique to perform measurements of dental arch and jaw arch lengths of study model casts with various depths. This finding is inconsistent with the results of the previous researches, which indicate that a simple computer program can increase study model cast measurement speed and that the more a practitioner is accustomed to the system, the more the speed will increase. ${ }^{1,13}$

In the present study, manual measurement takes less time since the process can be applied directly to the study model cast without any need to scan and place points on the monitor screen image of the cast as is necessary when the computer-aided technique is used.

\section{CONCLUSION}

Computer-aided measurement of dental arch and jaw arch lengths of a study model cast can be applied as an alternative to the manual technique.

However, careful considerations must be given regarding the biases that may result along with the increase of Spee's curve depths. How a practitioner places identification points on the monitor screen also plays an important role in determining the accuracy of computer-aided measurement. The computer-aided measurement technique takes more time than the manual one does. 


\section{REFERENCES}

1. Santoro M, et al. Comparison of measurement made on digital and plaster models. Am J Orthod 2003;57:101-5.

2. Quimby $M$. The accuracy and reliability of measurement made on computer-based digital models. Angle Orthod 2003;74:298 -303.

3. White L. Modern orthodontic diagnosis, treatment planning and therapy. California: Ormco Corporation; 1996 p. 26-7.

4. Hayasaki $\mathrm{H}$, et al. A new way of analyzing occlusion 3 dimensionally. Am $\mathrm{J}$ Orthod 2005;128:128-31.

5. Proffit WR, Fields HW. Contemporary orthodontics. $3^{\text {rd }}$ ed. St Louis: Mosby Inc; 2000 p. $165-70$

6. Schirmer U, Wiltshire W. Manual and computeraided space analysis: A compara tive study. Am J Orthod 1997;112: 676-80.

7. Champagne M. Reliability of measurement from photocopies of study models. J Clin
Orthod 1992;26:648-50.

8. Rhyden $\mathrm{H}$, et al. The Catenometer: a reliable device for estimating dental arch perimeter. Am J Orthod 1973;81:310-3.

9. Marcel T. Our digital model experience: a six month orthocad user report. The Pacific Coast Society of Orthodontists Bulletin. 2001;73.

10. Zilberman 0 , et al. Evaluation of the validity of tooth size and arch width measurement using conventional and three-dimensional virtual orthodontic models. Angle Orthod 2003;73:301-6.

11. Paredes $\mathrm{V}$, et al. New, fast and accurate procedure to calibrate a 2 dimensional digital measurement method. Am J Orthod 2005;127:518-9.

12. Rakosi T, Jonas I, Graber TM. Color atlas of dental medicine orthodontic diagnosis. New York: Theme Medical Publishers Inc.; 1993. p. 207-27.

13. Chen HY. Computer-aided space analysis. J Clin Orthod 1991;25:236-8. 